\title{
Acceptability of focused antenatal care by antenatal clinic attendees in Obio Cottage Hospital, Port Harcourt, Nigeria
}

\author{
Mabel Ikpim Ekott ${ }^{1}$, Edet Edet ${ }^{2}$, Ufuoma Ovwigho ${ }^{3}$, Soter Ameh ${ }^{4}$, Atim Udo ${ }^{1}$, Fajola Akinwunmi ${ }^{5}$ and Fakunle Babatunde ${ }^{6}$
}

*Correspondence: mabelekott@gmail.com

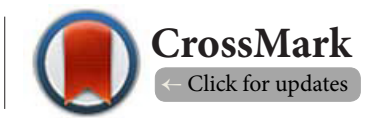

\begin{abstract}
'Department of Obstetrics and Gynecology, University of Calabar, Calabar, Nigeria. ${ }^{2}$ Department of Community Health, University of Calabar, Calabar, Nigeria.

${ }^{3}$ Clinical Governance Lead, The Shell Petroleum Development Company of Nigeria Limited, Port Harcourt, Nigeria.

${ }^{4}$ Department of Community Medicine, Faculty of Medicine and Dentistry, College of Medical Sciences, University of Calabar, Nigeria. ${ }^{5}$ Public Health Adviser, Community Health-Shell Health, Shell Petroleum Development Company Limited, Port Harcourt, Nigeria.

${ }^{6}$ Executive Director, Centre for Sustainable Access to Health in Africa (C-SAHA), Canada.
\end{abstract}

\begin{abstract}
Introduction: Focused antenatal care (FANC), based on fewer goal-oriented visits, is the WHO's recommended care for pregnant women. The objectives of the study were to assess the acceptability of FANC and barriers to its implementation at the hospital.

Methodology: This was a cross-sectional study conducted among antenatal clinic attendees between January and March 2011 at Obio Cottage Hospital, Port Harcourt Nigeria. Women were recruited by systematic sampling technique into the study. Questionnaires which sought demographic data, acceptability or rejection of fewer antenatal visits and reasons for decisions were administered to them. Data analysis was performed using Stata 10. Logistic regression analysis was performed to determine associations between demographic parameters and acceptance of FANC. Significance level was set at $\mathrm{P}<0.05$.

Results: The analysis was based on 456 out of 500 completed questionnaires. The mean age and parity of the women were $28.6 \pm 4.2$ and $1 \pm 1$ respectively. The mean number of preferred visits was $13.4 \pm 6.9$ visits, (IQR 9-18). Reduced visits were acceptable to $75 \%$ of the women. The main reason for accepting reduced visits was to save time $164(40.6 \%)$. The main reasons for rejecting reduced visits were for better monitoring of pregnancy $(35.1 \%)$ and early detection of problems $(21.6 \%)$. The likelihood of accepting fewer visits increased with age. $\mathrm{OR}=1.04 ; 95 \% \mathrm{CI}(1.09-1.10), \mathrm{P}=0.01$.
\end{abstract}

Conclusion: Focused antenatal care was acceptable to most women in the clinic. The concern it would compromise monitoring of pregnancy should be addressed during health education.

Keywords: Antenatal care, acceptability, barriers, blood donation, focused antenatal care, reduced visits

\section{Introduction}

Antenatal care was introduced in 1900 and has undergone some modifications. The traditional approach relies on 1215 visits during the course of pregnancy. This approach was accepted worldwide and has been the standard of obstetric care [1-5]. The risk-based approach to antenatal care was later incorporated into the antenatal care package. The risk-based approach utilizes multiple parameters to identify women deemed to be at high risk and, therefore, deserving closer care [5]. Later findings showed that only $10-30 \%$ of the women identified as high risk actually developed problem while the low risk group was found to develop unanticipated complications [6-8]. The risk-based approach therefore resulted in channeling resources toward a select few women who would not develop the anticipated complications to the detriment of the women deemed to be at low risk. Focused antenatal care was 
introduced in 2001 by the World Health Organization as an evidenced-based approach to caring for pregnant women [9]. It seeks to offer women individualized goal-oriented care that best meets the woman's health needs $[10,11]$. Women make fewer visits [4] but still receive health promotion, screening, detection and treatment of problems, prevention of diseases, complications and birth preparedness [10]. Concerns have been raised by women and service providers that the fewer visits would result in adverse maternal and foetal outcomes [12-14]. Villar [9] in a multicenter study that involved 12,568 women in the new model arm and 11,958 in the standard care arm showed that there was really no statistically significant difference in adverse maternal and foetal outcomes in women who received traditional care and focused antenatal care. However, the focused antenatal care model has been shown to increase utilization of skilled attendance at birth and it is also cost effective [15-17].

Focused antenatal care implementation involves dispensing with traditional antenatal practices such as routine weighing and height measurement for all women. Haematocrit is estimated once at 28 weeks of gestation instead of monthly as practiced our health facilities. These are practices women and healthcare providers had accepted as standard of care in antenatal practice. Modifying the routine practices raises concerns about the standard of care. As a result, the introduction of focused antenatal care package usually meets with resistance as women have come to expect these practices as the standard of care [18].

This study was undertaken as part of health system strengthening intervention program in Obio Cottage Hospital, Port Harcourt Nigeria. The aims of the study were to determine the acceptability of focused antenatal care prior to its introduction at the centre and to also determine issues that would constitute barriers to its implementation. The study also sought to determine women's opinion about blood donor pre-selection during antenatal period as a component of birth preparedness and preferred service provider prior to modifying pattern of care.

\section{Methodology}

\section{Study setting}

Obio Cottage Hospital is situated in Port-Harcourt, the capital of Rivers state in the South -South geo-political zone, Nigeria. The hospital offers maternal and child care services as well as general medical care to men and women. It is the pioneer hospital that implements the community healthcare insurance scheme which is supported by the Shell Petroleum Development Company. Health system strengthening intervention was commenced at the facility in 2010. The introduction of Community Health Insurance scheme at the facility in 2011 led to an upsurge in the number of clients accessing health care. The hospital has annual antenatal care attendees of 9857 women.

\section{Study design}

This was a cross-sectional study of pregnant women conducted between January and March 2011 in the hospital.

\section{Study population}

The study population consisted of pregnant women who had accessed antenatal care at the center two or more times during which they were recruited into the study. The women were educated on the focused antenatal care, its components and practice. The purpose of the study was explained to the women and consent to participate in the study was obtained from willing participants.

\section{Inclusion and exclusion criteria}

Those excluded were women on their first visit because we wanted women who had experienced antenatal care at the facility to be able to decide whether they would welcome the change in the pattern of care. We also excluded women with obstetric/medical emergencies like bleeding, asthma, severe preeclampsia and those who opted out of the study.

\section{Sample size estimation}

We used Leslie Kish's sample size formula to estimate a sample size of 383 study participants using a prevalence of $51 \%$ of women who visited ANC clinic at least four times, assuming a $95 \%$ standard normal deviate and $5 \%$ degree of accuracy. The minimum total sample size of 425 people was estimated after adjusting for $10 \%$ non-response.

\section{Sampling technique}

Using the facility roster $(n=1,500)$, the women were selected by systematic sampling using a sampling ratio of I in 3 until the sample size was completed.

\section{Training of interviewers and quality assurance}

Interviewers were trained on the questionnaire which had been pretested among post-partum women who delivered at the facility. After pretesting, the questionnaire was modified to remove ambiguities. Semi-structured self-administered questionnaires were distributed to the women. Trained interviewers administered the questionnaire and assisted women who could not self-complete the questionnaire. The questionnaire sought personal data from the women as well as their views about components of evidenced based antenatal care such as fewer visits, pre-blood donor selection during the antenatal period. They also advanced reasons for their responses which were recorded in the questionnaire.

\section{Data management and analysis}

Data analysis was performed using Stata 10 statistical software. Socio-demographic variables and other variables were reported using frequency tables. We did a binary logistic regression analysis to determine variables associated with acceptance of reduced visits. Independent variables in the regression analysis were age, parity, educational level, while acceptance of reduced visits was the binary outcome variable. 
Ekott et al. Research Journal of Women's Health 2017,

A variable was considered to be statistically significant if it's confidence interval excluded the null value of 1 .

\section{Result}

Four hundred and fifty-six out of 500 administered questionnaires were suitable for analysis, giving a response rate of $91.2 \%$. Table 1 shows the socio-demographic profile of the women. The mean age of the women was $28.6 \pm 4.2$ years and most of them were married 450 (98.7\%). Over half of the women $258(56.6 \%)$ had tertiary level education. The obstetric characteristics of the women consisted of 224 (49.1\%) nulliparae, 126 (27.6\%) primiparae, 104 (22.9\%) multiparas. Most of the women, $212(46.5 \%)$, were at gestational age of 14-28 weeks (second trimester).

The number of antenatal visits the women would like to make ranged from 5-40. Mean number of preferred visits was $13.4 \pm 6.9$ visits, (IQR 9-18). Three hundred and seventy seven $(82.7 \%)$ preferred to make at least 5 visits to the clinic, 77 (16.9\%) and $2(0.4 \%)$ would prefer $6-10$ visits and $>10$ visits respectively. Asked if they would accept making fewer visits that still met their health needs, 345 (75.7\%) would accept, while $111(24.3 \%)$ would not accept. We found that for every one year increase age, the likelihood of preferring fewer clinic visits increased by $4 \% \mathrm{OR}=1.04 ; 95 \% \mathrm{Cl}(1.09-1.10), \mathrm{P}=0.01$ (Table 2).

Table 1. The socio-demographic characteristics of the clients.

\begin{tabular}{ll}
\hline Variable & Number/Percentage \\
\hline Age (years) & $11(2.4)$ \\
\hline$<20$ & $92(20.2)$ \\
$20-25$ & $219(48.0)$ \\
$26-30$ & $106(23.3)$ \\
$31-35$ & $28(6.1)$ \\
$35-40$ & $0(0.0)$ \\
$>40$ & 456 \\
Total & $28.6 \pm 4.2$ years \\
Mean age & \\
\hline Marital status & $450(98.7)$ \\
\hline Married & $6(1.3)$ \\
Single/widowed/divorced & $456(100)$ \\
Total & \\
\hline Educational status & $2(0.4)$ \\
\hline No formal education & $12(2.6)$ \\
Primary & $184(40.4)$ \\
Secondary & $258(56.6)$ \\
Tertiary & $456(100)$ \\
Total & $224(49.1)$ \\
\hline Parity & $126(27.6$ \\
\hline 0 & $104(22.9)$ \\
1 & $2(0.4)$ \\
25 & $1 \pm 1$ \\
\hline mean parity & \\
\hline & \\
\hline & \\
\hline & \\
\hline
\end{tabular}

Table 2. Acceptability of Reduced visits.

\begin{tabular}{|c|c|c|}
\hline & \multicolumn{2}{|c|}{ Acceptance of reduced visits } \\
\hline & $\begin{array}{l}\text { Univariate } \\
\text { OR }(95 \% \mathrm{CI}) \text { p-value }\end{array}$ & $\begin{array}{l}\text { Multivariate } \\
\text { OR }(95 \% \mathrm{CI}) \text { p-value }\end{array}$ \\
\hline Age (years) & $1.04(1.09-1.10) 0.01$ & * \\
\hline $\begin{array}{l}\text { Gestational age of } \\
\text { present pregnancy } \\
<13 \text { weeks } \\
14-28 \text { weeks } \\
29-40 \text { weeks } \\
>40 \text { weeks }\end{array}$ & $\begin{array}{l}1 \\
1.14(0.73-1.79) 0.55 \\
1.44(0.58-3.70) 0.45 \\
4.31(0.55-33.89) 0.17\end{array}$ & * \\
\hline $\begin{array}{l}\text { Educational status } \\
\text { Primary } \\
\text { Secondary } \\
\text { Tertiary }\end{array}$ & $\begin{array}{l}1 \\
1.03(0.27-3.97) 0.97 \\
1.03(0.27-3.93) 0.07\end{array}$ & * \\
\hline $\begin{array}{l}\text { Parity } \\
0 \\
1-4 \\
>5\end{array}$ & $\begin{array}{l}1 \\
1.11(0.72-1.71) 0.63 \\
1.04(0.78-1.93) 0.77\end{array}$ & * \\
\hline $\begin{array}{l}\text { Number of clinic } \\
\text { visits in present } \\
\text { pregnancy }\end{array}$ & $0.96(0.87-1.05) 0.36$ & * \\
\hline
\end{tabular}

${ }^{*}$ Only age was significantly associated with acceptance of reduced visits in the univariate logistic regression model; hence, multivariate modelling was not done.

The main reasons for accepting reduced visits by 345 women were that it would save time $164(40.6 \%)$ and $64(16.5 \%)$ said they were healthy and so had no need for very frequent visits. However 81 (8.9\%) said it would save time and money (Table 3). The major reasons advanced by 111 women who rejected reduced visits in preference for multiple visits were multiple frequent visits would allow close monitoring of pregnancy 39 (35.1\%), early detection of problems $24(21.6 \%)$, allay anxiety $11(9.9 \%)$ while $13(11.7 \%)$ would like to comply with Doctors preferred schedule.

We also sought women's views about pre-delivery selection of blood donors as a component of birth preparedness; Among the 456 study participants, 298 (65.4\%) accepted they had relations who could donate blood for them if necessary. However $65.13 \%$ would be willing to have their relations screened during the antenatal period to determine compatibility for blood donation. Among those who were unwilling to have relations screened, the reasons were mainly because they have not asked their relations if they could donate blood 35 $(22.01 \%)$ and they were healthy so would not need blood transfusion 33 (20.75\%) Table 4.

\section{Discussion}

The study showed that majority of women in the centre who were already receiving traditional antenatal model of antenatal care preferred frequent visits during their antenatal care. They would accept reduced visits care model to save time. They were also willing to accept blood donor pre-selection as a component of birth preparedness. 
Ekott et al. Research Journal of Women's Health 2017,

Table 3. Reasons for Accepting/Rejecting Reduced visits.

\begin{tabular}{ll}
\hline $\begin{array}{l}\text { Reason for accepting reduced visits } \\
\text { N=345 }\end{array}$ & No/Percentage \\
\hline Saves time & $140(41)$ \\
Healthy & $64(18.6)$ \\
Saves time and money & $31(9.0)$ \\
Will improve care & $17(5.0)$ \\
Reduce stress/anxiety/crowd & $16(4.6)$ \\
Doctors discretion & $16(4.6)$ \\
No reason & $55(16.0)$ \\
\hline Reasons for rejecting reduced visits & Number/Percentage \\
N=111 & \\
\hline Monitoring of pregnancy & $39(35.1 \%)$ \\
Early detection of problems & $24(21.6)$ \\
Doctors preference & $13(11.7)$ \\
Allay Anxiety & $11(9.9)$ \\
Miss problem & $9(8.1 \%)$ \\
Satisfied with traditional method & $9(8.1 \%)$ \\
Other reasons & $6(5.4)$ \\
\hline
\end{tabular}

Table 4. Blood donor preselection during Antenatal period.

\begin{tabular}{ll}
\hline Do you have relations to donate blood & No (\%) \\
\hline Yes & $298(65.35)$ \\
No & $158(34.65)$ \\
\hline Willingness to have relations screened & \\
\hline Yes & $297(65.13)$ \\
No & $159(34.87)$ \\
\hline Reasons for not accepting Donor preselection/screening \\
\hline Has not asked relations & $35(22.01)$ \\
Healthy (will not need blood) & $33(20.75)$ \\
Not acceptable & $17(10.7)$ \\
Does not know relatives blood group & $15(9.4)$ \\
Religion & $7(4.4)$ \\
God will not allow need for blood & $2(1.3)$ \\
Did not need blood in previous deliveries & $2(1.3)$ \\
Relations are not around & $5(3.1)$ \\
Risk of transmission of infection & $1(0.6)$ \\
No reason & $41(25.8)$ \\
Total & 159 \\
\hline
\end{tabular}

The study showed that women preferred five or more visits during prenatal period. More visits as in the traditional approach is often perceived to mean better care and pregnancy outcome by women. This is not often the case as studies have shown that the maternal and fetal complication outcome are not necessarily different when women have fewer goaloriented visits, which is the concept of focused antennal care [18-21]. Three quarters of the women were willing to accept fewer visits. The reasons advanced were to save time. Waiting time in antenatal care has been a pervasive issue in antenatal service delivery as women spend up to 4-6 hours in antenatal clinics on a typical visit [22-25]. A similar study in Enugu State, south-east region of Nigeria showed that a lower percentage of women (20.3\%) accepted reduced visits. The Enugu study was conducted in a teaching hospital setting where more women with complicated pregnancies were more likely to receive care than at our facility. The majority of the acceptors in Enugu (65\%) gave convenience as the reason for accepting reduced visits [26]. Long waiting time in antenatal care clinic is associated with dissatisfaction with care [27-29]. An antenatal care practice that still meets the goal of antenatal care without adverse maternal or fetal outcome would save women's time. The quality time spent in the clinic during the fewer visits is tailored towards identifying the individual woman's need and addressing those needs.

A few of the women expressed concern that fewer visits could compromise monitoring of the pregnancy with the potential of late detection of complications. Women find multiple visits reassuring and it is also an excuse to socialize [30]. Where it is implemented, women have been generally satisfied with focused antenatal care, although women in developed countries have expressed dissatisfaction with their care. Concerns $[9,31-33]$ have been raised by women and service providers about fewer visits and spacing of visits. Secondary analysis of the WHO 2001 randomized control trial of focused antenatal care showed excess of foetal deaths in those who had fewer visits [34]. Studies have suggested that the long interval between visits from 32-36 weeks could result in non-detection of intrauterine growth restriction and other problems that could arise and cause foetal death in the third trimester [31,34,35]. In implementing focused antenatal care, health care workers must be trained to spend quality time screening, treating and addressing problems that could result in adverse maternal and fetal outcome. Fewer visits should not translate to poorer care.

Obstetric hemorrhage is the leading cause of maternal mortality [36-38]. Timely availability of blood for transfusion saves lives. Often, when women experience obstetric hemorrhage, blood often arrives too late or it is insufficient to save lives [39]. Pre-donor selection during antenatal period would ensure availability of blood for the woman when needed. Majority of the women had relatives who could donate blood if needed and where willing to have the relations screened for suitability for blood donation. A few would not want relations to donate blood for a variety of reasons ranging from false perception that they were healthy and so were unlikely to need blood to religious reasons and not knowing donors blood group. There is need to enlighten women about complication readiness including blood donation as complications could be unpredictable and ready availability of blood for transfusion would convert a possible fatal episode to near miss experience.

The views of the women were taken into consideration when focused antenatal care was later introduced. A five 
visit model of antennal care which would ensure that women whose pregnancy went beyond 40 weeks of gestation would be seen at 41 weeks and offered induction of labour was adopted. Fear that complications would be detected late was allayed by educating the women about danger signs in pregnancy and complication readiness. They were offered the opportunity to report to hospital even before their appointment dates if they had any concern about their pregnancies.

The strength of the study lies in the fact that the study was conducted in a busy obstetric setting in a cosmopolitan town. The findings of the study could be extrapolated to the general population as the hospital catered for a mix of women with diverse educational levels and background. The limitation of the study lies in the fact that the services are almost free for the patients, as a result there is increased patronage which makes women spend long periods in the clinic. This would make them readily accept fewer visits as it would save their time. There is need to seek the views of women who pay out of pocket to assess their views about focused antenatal care.

Focused antenatal care based on fewer visits was acceptable to majority of women in the health facility. The concern that it could compromise monitoring of pregnancy and detection of problems raised by few women should be addressed during health education component of antenatal care.

\section{Competing interests}

The authors declare that they have no competing interests.

Authors' contributions

\begin{tabular}{|l|c|c|c|c|c|c|c|}
\hline Authors' contributions & MIE & EE & UO & SA & AU & FA & FB \\
\hline Research concept and design & $\checkmark$ & $\checkmark$ & $\checkmark$ & -- & -- & -- & -- \\
\hline Collection and/or assembly of data & $\checkmark$ & $\checkmark$ & $\checkmark$ & -- & -- & -- & -- \\
\hline Data analysis and interpretation & $\checkmark$ & $\checkmark$ & $\checkmark$ & $\checkmark$ & $\checkmark$ & $\checkmark$ & $\checkmark$ \\
\hline Writing the article & $\checkmark$ & $\checkmark$ & -- & -- & -- & -- & -- \\
\hline Critical revision of the article & $\checkmark$ & $\checkmark$ & $\checkmark$ & $\checkmark$ & $\checkmark$ & $\checkmark$ & $\checkmark$ \\
\hline Final approval of article & $\checkmark$ & $\checkmark$ & $\checkmark$ & $\checkmark$ & $\checkmark$ & $\checkmark$ & $\checkmark$ \\
\hline Statistical analysis & -- & -- & -- & $\checkmark$ & -- & -- & -- \\
\hline
\end{tabular}

Acknowledgement

The fund for the research was provided by Community Health Department Shell Development Corporation, Port Harcourt. We are grateful to the doctors and nurses at Obio Cottage Hospital who administered the questionnaire and our pregnant women who participated in the study.

Publication history

Editor: Erich Cosmi, University of Padua, Italy.

Received: 18-Nov-2016 Final Revised: 15-Dec-2016

Accepted: 26-Dec-2016 Published: 04-Jan-2017

\section{References}

1. Alexander GR and Kotelchuck M. Assessing the role and effectiveness of prenatal care: history, challenges, and directions for future research. Public Health Rep. 2001; 116:306-16. | PubMed Abstract | PubMed FullText

2. Oakley A. The Origin and Development of Antenatal Care. In: Enkin M, Chalmers I (ed). Effectiveness and Satisfaction in Antenatal Care.
Philadelphia: Spastics International Medical Publications. 1982; 1-21.

3. Hall MH. Rationalization of Antenatal Care. Lancet. 2001; 357:1546. | Article

4. Majoko F, Munjanja SP, Nystrom L, Mason E and Lindmark G. Randomised controlled trial of two antenatal care models in rural Zimbabwe. BJOG. 2007; 114:802-11. | Article | PubMed

5. Chard T, Learmont J, Carroll S, Hudson C, Lloyd DS and Sloan D. Evaluation of a fetal risk-scoring system. Am J Perinatol. 1992; 9:388-93. | Article | PubMed

6. Shiono PH and Klebanoff MA. A Review of Risk Scoring For Preterm Babies. Clin Perinatol. 1993; 20:107-25.

7. Carroli G, Rooney $C$ and Villar J. How effective is antenatal care in preventing maternal mortality and serious morbidity? An overview of the evidence. Paediatr Perinat Epidemiol. 2001; 15 Suppl 1:1-42. | Article I PubMed

8. Abou-Zahr CL and Wardlaw T. Antenatal Care in Developing Countries. Promises, Achievements and Missed Opportunities: An Analysis of Trends, Levels and Differentials. 1990-2001. Geneva: WHO. 2003; 1-32. I Pdf

9. Villar J, Ba'aqeel H, Piaggio $G$, Lumbiganon $P$, Miguel Belizan J, Farnot $U$, Al-Mazrou Y, Carroli G, Pinol A, Donner A, Langer A, Nigenda G, Mugford $\mathrm{M}$ and Fox-Rushby J. WHO antenatal care randomised trial for the evaluation of a new model of routine antenatal care. Lancet. 2001; 357:1551-64. | Article | PubMed

10. Lincetto O, Mothebesoane-Anoh S, Gomez P and Munjanja SP. Antenatal Care. In:Lawn J, Kerber K (eds.) Opportunities for Africa's Newborn:Practical Data, Policy and Programmatic Support for Newborn Care in Africa. Cape Town, South Africa: PMNCH. 2006; 51-62. | Pdf

11. Von Both C, Flessa S, Makuwani A, Mpembeni R and Jahn A. How much time do health services spend on antenatal care? Implications for the introduction of the focused antenatal care model in Tanzania. BMC Pregnancy Childbirth. 2006; 6:22. | Article | PubMed Abstract | PubMed FullText

12. Mathole T, Lindmark $G$, Majoko $F$ and Ahlberg BM. A qualitative study of women's perspectives of antenatal care in a rural area of Zimbabwe. Midwifery. 2004; 20:122-32. | Article | PubMed

13. Sanders J, Somerset M, Jewell D and Sharp D. To see or not to see? Midwives' perceptions of reduced antenatal attendances for 'low-risk' women. Midwifery. 1999; 15:257-63. | Article | PubMed

14. Langer A, Villar J, Romero M, Nigenda G, Piaggio G, Kuchaisit C, Rojas G, Al-Osimi M, Miguel Belizan J, Farnot U, Al-Mazrou Y, Carroli G, Ba'aqeel $H$, Lumbiganon P, Pinol A, Bergsjo P, Bakketeig L, Garcia J and Berendes $H$. Are women and providers satisfied with antenatal care? Views on a standard and a simplified, evidence-based model of care in four developing countries. BMC Womens Health. 2002; 2:7. | Article | PubMed Abstract | PubMed FullText

15. Ouma PO, van Eijk AM, Hamel MJ, Sikuku ES, Odhiambo FO, Munguti KM, Ayisi JG, Crawford SB, Kager PA and Slutsker L. Antenatal and delivery care in rural western Kenya: the effect of training health care workers to provide "focused antenatal care". Reprod Health. 2010; 7:1. | Article | PubMed Abstract | PubMed FullText

16. Magoma M, Requejo J, Campbell O, Cousens S, Merialdi M and Filippi $V$. The effectiveness of birth plans in increasing use of skilled care at delivery and postnatal care in rural Tanzania: a cluster randomised trial. Trop Med Int Health. 2013; 18:435-43. | Article | PubMed

17. Soubeiga D, Sia D and Gauvin L. Increasing institutional deliveries among antenatal clients: effect of birth preparedness counselling. Health Policy Plan. 2014; 29:1061-70. | Article | PubMed Abstract | PubMed FullText

18. Binstock MA and Wolde-Tsadik G. Alternative prenatal care. Impact of reduced visit frequency, focused visits and continuity of care. J Reprod Med. 1995; 40:507-12. | PubMed

19. McDuffie RS, Jr., Beck A, Bischoff K, Cross J and Orleans M. Effect of frequency of prenatal care visits on perinatal outcome among low-risk women. A randomized controlled trial. JAMA. 1996; 275:847-51. | Article I PubMed

20. Walker DS and Koniak-Griffin D. Evaluation of a reduced-frequency 
Ekott et al. Research Journal of Women's Health 2017,

http://www.hoajonline.com/journals/pdf/2054-9865-4-1.pdf

prenatal visit schedule for low-risk women at a free-standing birthing center. J Nurse Midwifery. 1997; 42:295-303. | PubMed

21. Partridge CA and Holman JR. Effects of a reduced-visit prenatal care clinical practice guideline. J Am Board Fam Pract. 2005; 18:555-60. I Article I PubMed

22. Williamson S and Thomson AM. Women's satisfaction with antenata care in a changing maternity service. Midwifery. 1996; 12:198-204. | Article I PubMed

23. Birungi $\mathrm{H}$ and Onyango-Ouma W. Acceptability and Sustainability of the WHO Focused Antenatal Care package in Kenya. Nairobi Kenya. Frontiers of Reproductive Health program. Institute of African Studies, University of Nairobi. 2006; 1-45.

24. Esimai $O A$ and Omoniyi-Esan GO. Wait time and service satisfaction at Antenatal Clinic, Obafemi Awolowo University Ile-Ife. East Afr J Public Health. 2009; 6:309-11. I Article I PubMed

25. Ekott MI, Ovwigho U, Ehigiegba A, Fajola A and Fakunle B. Perception of pregnant women about antenatal care in a cottage hospital in Port Harcourt, Nigeria. J Community Health. 2013; 38:360-5. I Article | PubMed

26. Aniebue UU and Aniebue PN. Women's perception as a barrier to focused antenatal care in Nigeria: the issue of fewer antenatal visits. Health Policy Plan. 2011; 26:423-8. | Article | PubMed

27. Nisar $\mathrm{N}$ and Amjad R. Pattern of antenatal care provided at a public sector hospital Hyderabad Sindh. J Ayub Med Coll Abbottabad. 2007; 19:11-3. | Pdf | PubMed

28. Ghobashi M and Khandekar R. Satisfaction among Expectant Mothers with Antenatal Care Services in the Musandam Region of Oman. Sultan Qaboos Univ Med J. 2008; 8:325-32. I PubMed Abstract I PubMed FullText

29. Kowalewski M, Jahn A and Kimatta SS. Why do at-risk mothers fail to reach referral level? Barriers beyond distance and cost. Afr J Reprod Health. 2000; 4:100-9. | Article | PubMed

30. Umeora OU, Ejikeme BN, Sunday-Adeoye I and Ogu RN. Implementing the new WHO antenatal care model: voices from end users in a rural Nigerian community. Niger J Clin Pract. 2008; 11:260-4. | Article | PubMed

31. Dowswell T, Carroli G, Duley L, Gates S, Gulmezoglu AM, Khan-Neelofur D and Piaggio GG. Alternative versus standard packages of antenatal care for low-risk pregnancy. Cochrane Database Syst Rev. 2010; CD000934. I Article | PubMed Abstract | PubMed FullText

32. Nigenda G, Langer A, Kuchaisit C, Romero M, Rojas G, Al-Osimy M, Villar J, Garcia J, Al-Mazrou Y, Ba'aqeel H, Carroli G, Farnot U, Lumbiganon P, Belizan J, Bergsjo P, Bakketeig L and Lindmark G. Womens' opinions on antenatal care in developing countries: results of a study in Cuba, Thailand, Saudi Arabia and Argentina. BMC Public Health. 2003; 3:17. | Article | PubMed Abstract | PubMed FullText

33. Carroli G, Rooney $C$ and Villar J. How effective is antenatal care in preventing maternal mortality and serious morbidity? An overview of the evidence. Paediatr Perinat Epidemiol. 2001; 15 Suppl 1:1-42. | Article I PubMed

34. Vogel JP, Habib NA, Souza JP, Gulmezoglu AM, Dowswell T, Carroli G, Baaqeel HS, Lumbiganon P, Piaggio G and Oladapo OT. Antenatal care packages with reduced visits and perinatal mortality: a secondary analysis of the WHO Antenatal Care Trial. Reprod Health. 2013; 10:19. | Article | PubMed Abstract | PubMed FullText

35. Hofmeyr GJ and Hodnett ED. Antenatal care packages with reduced visits and perinatal mortality: a secondary analysis of the WHO antenatal care trial - Comentary: routine antenatal visits for healthy pregnant women do make a difference. Reprod Health. 2013; 10:20. Article | PubMed Abstract | PubMed FullText

36. Khan KS, Wojdyla D, Say L, Gulmezoglu AM and Van Look PF. WHO analysis of causes of maternal death: a systematic review. Lancet. 2006; 367:1066-74. | Article | PubMed

37. Liang J, Dai L, Zhu J, Li X, Zeng W, Wang H, Li Q, Li M, Zhou R and Wang Y. Preventable maternal mortality: geographic/rural-urban differences and associated factors from the population-based Maternal Mortality Surveillance System in China. BMC Public Health. 2011; 11:243. | Article | PubMed Abstract | PubMed FullText

38. Ujah IA, Aisien OA, Mutihir JT, Vanderjagt DJ, Glew RH and Uguru VE. Factors contributing to maternal mortality in north-central Nigeria: a seventeen-year review. Afr J Reprod Health. 2005; 9:27-40. | Article | PubMed

39. Agan TU, Archibong El, Ekabua JE, Ekanem El, Abeshi SE, Edentekhe T and Bassey EE. Trends in maternal mortality at the University of Calabar Teaching Hospital, Nigeria, 1999-2009. Int J Womens Health. 2010; 2:249-54. | Article | PubMed Abstract | PubMed FullText

\section{Citation:}

Ekott MI, Edet E, Ovwigho U, Ameh S, Udo A, Akinwunmi $\mathrm{F}$ and Babatunde F. Acceptability of focused antenatal care by antenatal clinic attendees in Obio Cottage Hospital, Port Harcourt, Nigeria. Res J Womens Health. 2017; 4:1. http://dx.doi.org/10.7243/2054-9865-4-1 